\title{
Investigation on the wear of spur gears generated by modified cutter
}

\author{
Fangyan ZHENG ${ }^{1,3,}$, Jun ZHANG ${ }^{2}$, Ligang YAO ${ }^{2}$, Rulong TAN ${ }^{3}$ \\ ${ }^{1}$ School of Automotive Engineering, Wuhan University of Technology, Wuhan 430070, China \\ ${ }^{2}$ School of Mechanical Engineering and Automation, Fuzhou University, Fuzhou 350116, China \\ ${ }^{3}$ School of Mechanical Engineering, Chongqing University of Technology, Chongqing 400000, China \\ Received: 01 April 2018 / Revised: 19 February 2019 / Accepted: 21 October 2019 \\ (C) The author(s) 2019.
}

\begin{abstract}
Tooth surface wear damage is one of the main causes of gearing system failure. Excessive wear leads to tooth profile loss and an increase in transmission errors, as the worn gear surfaces are no longer conjugate. Thus, the enhancement of gear durability against wear is important for gear application. Recent works show that cutter modification can aid in reducing the tool wear in gear processing, while the wear performance of the gears produced by modified cutters is still unknown. Therefore, this study focuses on the wear performance of the gear generated by modified cutter. Numerical results show that the wear resistance can be enhanced through proper cutter modification.
\end{abstract}

Keywords: gear wear; cutter modification; gear modification

\section{Introduction}

Spur gears, which are the key components in many mechanical systems [1-3], are widely used in modern industries, such as aerospace, marine, agriculture, and construction [4-6]. As advanced driving systems enable high speed, wear damages have become the main cause of failure of gear components [7-10].

Thus, gear wear has been actively researched in recent times, and some of these studies are focused on wear mechanism and wear calculation methods.

For mild surface wear, Archard's wear model [11] is widely used, although it is rather imperfect. As gear wear is usually regarded as a special case of surface wear, research on gear wear can be dated back to the doctoral thesis of Andersson [12]. Wu and Chen [13] then proposed a simple wear calculation method for spur gear and revealed that the worst wear occurred at the beginning of the gear mesh (tooth tips of the driven gear). Flodin and Andersson then published a series of works on spur and helix gear wear prediction [14, 15], in which a modified Archard's wear model was established, a "single point observation principle" was used, and the tooth stiffness was considered through an empirical model developed by Simon [16]. Brauer and Andersson [17] investigated the wear in spur gears caused by interference using a mixed finite element and analytical approach. They validated that the interference was caused by deviation from the ideal gear geometry and unfavorable deformation during operation; Bajpai et al. [18] proposed a wear prediction methodology for spur and helical gears using a finite element-based gear contact mechanics model in conjunction with Archard's wear formulation to predict the wear of contacting tooth surfaces. They also investigated the influence of tooth profile deviation through intentional tooth profile modification [19]; Tunalioğlu and Tuç [20] researched the wear in internal gears with the combination of theoretical calculation and experiment. They designed and manufactured a fatigue and wear test equipment that was similar to Forschungsstelle für Zahnrader

* Corresponding author: Fangyan ZHENG, E-mail: 382280761@qq.com 


\begin{tabular}{|c|c|c|c|}
\hline \multicolumn{4}{|c|}{ Nomenclature } \\
\hline $\begin{array}{l}l_{p f}(u, r) \\
\xi\end{array}$ & $\begin{array}{l}\text { Cutter tooth modification function } \\
\text { Tooth profile modification magnitude }\end{array}$ & $n_{F i}\left(u_{i}, r_{i}, \varphi_{I}\right)$ & $\begin{array}{l}\text { Tooth normals of drive gear in ground } \\
\text { coordinate system in TCA }\end{array}$ \\
\hline $\begin{array}{l}\mu_{0} \\
r_{c}(u, r)\end{array}$ & $\begin{array}{l}\text { Tooth profile modification range } \\
\text { Tooth surface of the cutter with parabolic }\end{array}$ & $n_{F o}\left(u_{o}, r_{o}, \varphi_{o}\right)$ & $\begin{array}{l}\text { Tooth normals of driven gear in ground } \\
\text { coordinate system in TCA }\end{array}$ \\
\hline$n_{\mathrm{c}}(u, r)$ & $\begin{array}{l}\text { modification } \\
\text { Tooth normals of the cutter with parabolic }\end{array}$ & $v_{i}\left(u_{i}, r_{i}, \varphi_{I}\right)$ & $\begin{array}{l}\text { Velocity of contact points in drive gear } \\
\text { in TCA }\end{array}$ \\
\hline $\mathrm{S}_{\mathrm{r}}$ & $\begin{array}{l}\text { modification } \\
\text { Translation distance of the rack in gear }\end{array}$ & $v_{\mathbf{o}}\left(u_{0}, r_{0}, \varphi_{0}\right)$ & $\begin{array}{l}\text { Velocity of contact points in driven gear } \\
\text { in TCA }\end{array}$ \\
\hline$\varphi_{\mathrm{g}}$ & $\begin{array}{l}\text { generating } \\
\text { Rotating angle of gear in gear generating }\end{array}$ & $v_{i o}\left(u_{i}, r_{i}, u_{0}, r_{0}\right.$, & $\begin{array}{ll}\left.\varphi_{I}, \varphi_{0}\right) & \text { Relative velocity of the contact } \\
\text { points in TCA }\end{array}$ \\
\hline$r_{\mathrm{g}}$ & Pitch radius of the gear & $K_{i}$ & Curvature of drive gear \\
\hline$r_{\mathrm{g}}\left(u, r, \varphi_{\mathrm{g}}\right)$ & Envelope surface of the rack & $K_{o}$ & Curvature of driven gear \\
\hline & $\begin{array}{l}\text { Velocity of generated gear } \\
\text { Velocity of rack }\end{array}$ & $K_{i o}$ & $\begin{array}{l}\text { Relative curvature between the drive } \\
\text { and driven gears }\end{array}$ \\
\hline$v_{\mathrm{cg}}\left(u, r, \varphi_{\mathrm{g}}\right)$ & $\begin{array}{l}\text { Relative velocity between the rack and } \\
\text { the gear }\end{array}$ & $\begin{array}{l}n_{\mathrm{cj}} \\
T_{o}\end{array}$ & $\begin{array}{l}\text { Number of instant contact points } \\
\text { Total torque applied to driven gear }\end{array}$ \\
\hline$n_{0 c}\left(u, r, \varphi_{g}\right)$ & $\begin{array}{l}\text { Tooth normals of the rack in the ground } \\
\text { coordinate system }\end{array}$ & $\begin{array}{c}\boldsymbol{r}_{j} \\
\boldsymbol{F}_{j}\end{array}$ & $\begin{array}{l}\text { Position vector in each contact point } \\
\text { Normal contact force in each contact point }\end{array}$ \\
\hline$r_{\mathrm{G}}(u, r)$ & Tooth surface of the modified spur gear & $C_{j}$ & Comprehensive stiffness matrix in contact \\
\hline$n_{\mathrm{G}}(u, r)$ & Tooth normals of the modified spur gear & $\delta_{j}$ & Total deformation of the gear teeth \\
\hline$\varphi_{i}$ & $\begin{array}{l}\text { Rotating angle of drive gear in tooth } \\
\text { contact analysis (TCA) }\end{array}$ & $\begin{array}{l}\boldsymbol{n}_{j} \\
P_{\mathrm{H}}\end{array}$ & $\begin{array}{l}\text { Unit normal vector of the contact point } \\
\text { Maximum pressure in each contact point }\end{array}$ \\
\hline$\varphi_{o}$ & Rotating angle of driven gear in TCA & $b$ & Contact width \\
\hline$E_{I O}$ & Center distance of the gear pair & $l$ & Tooth width \\
\hline$r_{\mathrm{G} i}(u, r)$ & Tooth surface of drive gear in TCA & $a_{j}$ & Semi-Hertzian contact width \\
\hline$r_{\mathrm{G} o}(u, r)$ & Tooth surface of driven gear in TCA & $v_{i}$ & Poisson's ratio for drive gear \\
\hline$r_{F i}\left(u, r, \varphi_{I}\right)$ & $\begin{array}{l}\text { Tooth surface of drive gear in ground } \\
\text { coordinate system in TCA }\end{array}$ & $\begin{array}{l}v_{o} \\
h\end{array}$ & $\begin{array}{l}\text { Poisson's ratio for driven gear } \\
\text { wear depth }\end{array}$ \\
\hline$r_{F o}\left(u, r, \varphi_{o}\right)$ & $\begin{array}{l}\text { Tooth surface of driven gear in ground } \\
\text { coordinate system in TCA }\end{array}$ & $\begin{array}{l}K_{w} \\
s_{i}\end{array}$ & $\begin{array}{l}\text { Wear coefficient } \\
\text { Slider distance in each micro segment }\end{array}$ \\
\hline
\end{tabular}

und Getreibbau [21] closed circuit power circulation system in working principle. Masjedi and Khonsari [22] developed a procedure to predict film thickness, traction coefficient, and wear rate with provision for the interactions between the surface asperities of the teeth of gear. Additionally, Henneberg et al. [23] proposed a quasi-stationary approach to achieve particle concentration and distribution in gear oil for performing the wear estimation.

Some other works have focused on enhancing the wear resistance to render the gear system more durable: Mao [24] adopted the micro-geometry modification method to investigate gear fatigue wear reduction and proposed an optimized micro-geometry gear tooth through advanced non-linear finite element analysis. İmrek and Düzcükoğlu [25] focused on the relationship between wear and tooth width modification in spur gears. They indicated that the wear depth of the modified gear along the meshing area was almost uniform and better than that of the unmodified gear; Karpat and Ekwaro-Osire [26] studied the influence of tip relief modification on spur gears with asymmetric teeth to reveal that an excessive increase in tip relief modification should be avoided, and the level of 
excessive increase was based on tip relief configuration; PrabhuSekar and Sathishkumar [27, 28] proposed a method for enhancing the wear resistance of normal contact ratio spur gear pairs through non-standard gears. They showed that the use of non-standard pinion and gear of unequal tooth thickness could aid in reducing the wear damage. Zhou et al. [29] investigated the normal and tangential oil film stiffness of modified spur gears with non-Newtonian elastohydrodynamic lubrication. They revealed that the modification was valid for inhibiting the jump of oil film stiffness and improving the gear wear resistance. These studies together established that reasonable flank modification could aid in enhancing the gear wear resistance. However, on one hand, as these works are conducted based on an assumed gear tooth modified geometry, realizing their proposed methods in practice is difficult (gear modification is generally obtained by cutter modification) [30-32]. On the other hand, as the modified gears are not conjugate, transmission errors and change of dynamic performance may occur [33].

Some studies focused on the tool wear that happens during the cutting process. Bouzakis et al. [34, 35] established a sophisticated numerical model to predict tool wear in gear hobbing cutting process and revealed that coated hob teeth performed better than the uncoated ones, and tooth profile geometry influenced tool wear. Claudin and Rech [36] developed a new rapid characterization method to enhance the wear resistance of hob in gear manufacturing and established that cutter edge geometry also influenced tool wear; Karpuschewski et al. [37] investigated the geometrical influence of tool profile on wear behavior in gear hobbing. This study suggested that $30 \%$ of the total piece cost for the hobbing process can be reduced with the application of optimized tool profiles and corresponding cutting parameters. These studies established that tool profile modification could aid in enhancing the wear resistance of the tool in the cutting process. However, the wear performance of the gear cut by modified cutter remained unknown.

Based on all the works discussed so far, this study aims to investigate the wear performance of spur gears with tooth profiles generated by modified hobbing cutters. Firstly, the tooth geometry of spur gears generated by modified cutters is obtained, including the tooth modification of basic rack generator and tooth surface of the modified gear. Then the tooth wear calculation is discussed in detail, including the tooth contact analysis, contact force calculation, and wear depth calculation. Finally, the wear performance under different cutter modifications is discussed by considering the planet gear and sun gear of an epicyclical transmission used in the wheel hub of an electric automobile as an example, establishing that wear resistance can be enhanced with appropriate cutter modification.

\section{Tooth geometry of spur gears with cutter modification}

Face-hobbing cutter is widely used in the manufacture of external spur gears [38]. As the basic geometry of the cutter includes a rack, the cutting process can be regarded as the meshing of a gear and a rack [39]. The modified gear tooth geometry should thus be deduced based on the modified cutter and the kinematic relations generated.

\subsection{Tooth modification for the rack generator}

As is shown in Fig. 1, the basic unmodified tooth profile appears to be a straight line with a pressure angle $\alpha$ relative to the pitch line. The coordinate system $S_{v}\left(O_{v}-x_{v} y_{v} z_{v}\right)$ is attached at the middle of the rack with its $x_{v}$-axis along the pitch line of the rack. To modify the tooth profile, coordinate systems $S_{l}\left(O_{l}-x_{l} y_{l} z_{l}\right)$ and $S_{r}\left(O_{r}-x_{r} y_{r} z_{r}\right)$ are established with their corresponding $x_{l}$-axis and $x_{r}$-axis along the basic

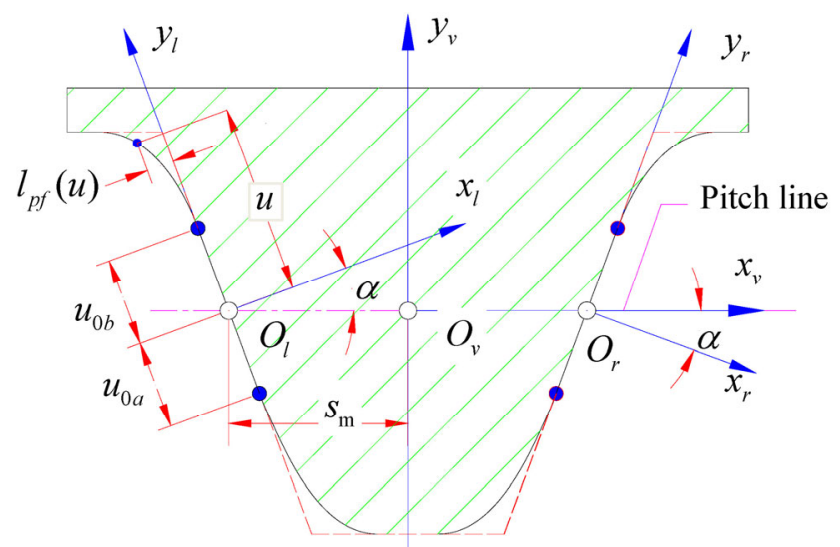

Fig. 1 Modification of tooth profile for the basic rack. 
unmodified tooth profile. In coordinate systems $S_{l}$ and $S_{r}$, the tooth profile is defined by parameter $u$. Two parameters $u_{0 a}$ and $u_{0 b}$ are used to define the starting and ending points of modification, and function $l_{p f}(u)$ is used to present the offset of the modification. In this study, drawn from the research in Ref. [40], a parabolic function is used to modify the tooth profile, which can be defined in coordinate systems $S_{l}$ and $S_{r}$ as follows:

$$
l_{p f}(u, r)=\left\{\begin{array}{l}
\xi\left(u-u_{0}\right)^{2}, \quad u>u_{0} \\
0, \quad-u_{0} \leq u \leq u_{0} \\
-\xi\left(u-u_{0}\right)^{2}, \quad u<-u_{0}
\end{array}\right.
$$

where $u_{0}=\mu_{0} h_{f}(r) / \cos (\alpha), \xi$ is used to define the tooth profile modification magnitude, and $\mu_{0}$ is used to define the tooth profile modification range.

The origins of coordinate systems $S_{l}$ and $S_{r}$, respectively $O_{l}$ and $O_{r}$, are the intersection points of the pitch line and unmodified tooth profile. Their distance from $O_{v}$ denotes the tooth thickness modification of the gear $\Delta s_{\mathrm{m}}$.

Thus, the tooth surface of the cutter with parabolic modification can be obtained as follows:

$$
r_{\mathrm{c}}(u, r)=\boldsymbol{M}_{v l, r}\left[ \pm l_{p f}(u) \quad u \quad 0 \quad 1\right]^{\mathrm{T}}
$$

where $\boldsymbol{M}_{v l, r}=\left[\begin{array}{cccc}\cos (\alpha) & \pm \sin (\alpha) & 0 & \pm s_{\mathrm{m}}(r) \\ \mp \sin (\alpha) & \cos (\alpha) & 0 & 0 \\ 0 & 0 & 0 & 0 \\ 0 & 0 & 0 & 1\end{array}\right]$.

Besides, the normals of the cutter are defined as follows:

$$
n_{\mathrm{c}}(u, r)=\frac{\mathrm{d} r_{\mathrm{c}}(u, r)}{\mathrm{d} u} \times \frac{\mathrm{d} r_{\mathrm{c}}(u, r)}{\mathrm{d} r}
$$

\subsection{Tooth surface of the modified gear}

As shown in Fig. 2, $O_{0}$ is the center of the gear, and $O_{1}$ is the contact point between the pitch line of the rack and pitch circle of the gear. Four coordinate systems are established to present the generated kinematics. The coordinate system $S_{0}\left(O_{0}-x_{0} y_{0} z_{0}\right)$ is fixed on the ground with $x_{0}$-axis along $\mathrm{O}_{0} \mathrm{O}_{1}$, while the coordinate system $S_{1}\left(O_{1}-x_{1} y_{1} z_{1}\right)$ is fixed on the ground with $x_{1}$-axis along the direction of $x_{0}$-axis

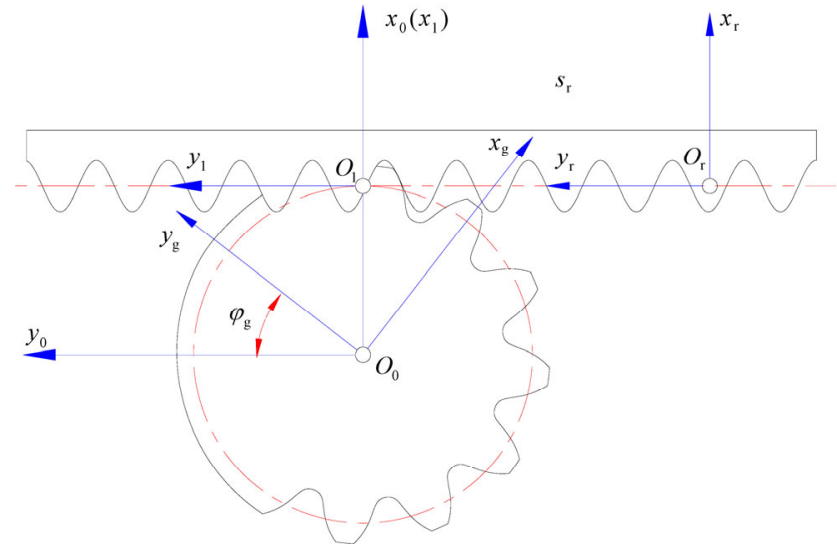

Fig. 2 Kinematics for the generation of helix gear by rack generator.

The coordinate system $S_{\mathrm{g}}\left(O_{0}-x_{\mathrm{g}} y_{\mathrm{g}} z_{\mathrm{g}}\right)$ is attached on the gear with $z_{\mathrm{g}}$-axis along the gear axis, and its angle relative to $S_{0}$ is the rotating angle of the gear. The coordinate system $S_{\mathrm{r}}\left(O_{\mathrm{r}}-x_{\mathrm{r}} y_{\mathrm{r}} z_{\mathrm{r}}\right)$ is attached on the rack with $y_{\mathrm{r}}$-axis along the translational direction of the rack, and its distance from $S_{1}$ denotes the translation distance of the rack $s_{\mathrm{r}}$.

Based on pure rotation relation, the angle of gear and the translation of the rack must fulfill the following criteria [41]:

$$
S_{\mathrm{r}}=\varphi_{\mathrm{g}} r_{\mathrm{g}}
$$

where $r_{\mathrm{g}}$ is the pitch radius of the gear.

With the coordinate systems established, the relationship between the rack and gear can be obtained as follows:

$$
M_{\mathrm{gr}}\left(\varphi_{\mathrm{g}}\right)=M_{\mathrm{g} 0}\left(\varphi_{\mathrm{g}}\right) M_{01} M_{1 \mathrm{r}}\left(s_{\mathrm{r}}\right)
$$

where

$$
M_{1 \mathrm{r}}\left(\varphi_{\mathrm{g}}\right)=\left[\begin{array}{cccc}
1 & 0 & 0 & 0 \\
0 & 1 & 0 & -\varphi_{\mathrm{g}} r_{\mathrm{g}} \\
0 & 0 & 1 & 0 \\
0 & 0 & 0 & 1
\end{array}\right], \quad M_{01}=\left[\begin{array}{cccc}
1 & 0 & 0 & r_{\mathrm{g}} \\
0 & 1 & 0 & 0 \\
0 & 0 & 1 & 0 \\
0 & 0 & 0 & 1
\end{array}\right]
$$

and

$$
M_{\mathrm{g} 0}\left(\varphi_{\mathrm{g}}\right)=\left[\begin{array}{cccc}
\cos \left(\varphi_{\mathrm{g}}\right) & -\sin \left(\varphi_{\mathrm{g}}\right) & 0 & 0 \\
\sin \left(\varphi_{\mathrm{g}}\right) & \cos \left(\varphi_{\mathrm{g}}\right) & 0 & 0 \\
0 & 0 & 1 & 0 \\
0 & 0 & 0 & 1
\end{array}\right]
$$


Thus, the envelope surface of the rack is defined as follows:

$$
r_{\mathrm{g}}\left(u, r, \varphi_{\mathrm{g}}\right)=M_{\mathrm{gr}}\left(\varphi_{\mathrm{g}}\right) r_{\mathrm{c}}(u, r)
$$

The meshing equation can be obtained as follows [42]:

$$
n_{0 \mathrm{c}}(u, r) \cdot v_{\mathrm{cg}}\left(u, r, \varphi_{\mathrm{g}}\right)=0
$$

Suppose the velocity of the generated gear $\omega_{\mathrm{g}}=1$, the velocity of the generator must be $v_{\mathrm{c}}=r_{\mathrm{g}} \varphi_{\mathrm{g}}$, the normals of the generator and the relative velocity in the coordinate system $S_{0}$ can be calculated as follows:

$$
\left\{\begin{array}{l}
v_{\mathrm{cg}}\left(u, r, \varphi_{\mathrm{g}}\right)=\left[\begin{array}{l}
1 \\
0 \\
0
\end{array}\right] \times M_{01} M_{1 \mathrm{r}}\left(\varphi_{\mathrm{g}}\right) r_{\mathrm{c}}(u, r)-M_{01} M_{1 \mathrm{r}}\left(\varphi_{\mathrm{g}}\right)\left[\begin{array}{c}
0 \\
v_{\mathrm{c}} \\
0
\end{array}\right] \\
n_{0 \mathrm{c}}\left(u, r, \varphi_{\mathrm{g}}\right)=M_{01} M_{1 \mathrm{r}}\left(\varphi_{\mathrm{g}}\right) n_{\mathrm{c}}(u, r)
\end{array}\right.
$$

Equation (8) is solved using a numerical method. When the parameter $\varphi_{\mathrm{g}}$ is obtained as $\varphi_{\mathrm{g}}=\varphi_{\mathrm{g}}(u, r)$ and substituted into Eq. (6), the final tooth surface of the modified spur gear can be obtained as follows:

$$
r_{\mathrm{G}}(u, r)=r_{\mathrm{g}}\left[\mu, r, \varphi_{\mathrm{g}}(u, r)\right]
$$

Therefore, the tooth normal is obtained as follows:

$$
n_{\mathrm{G}}(u, r)=M_{\mathrm{g} 0}\left[\varphi_{\mathrm{g}}(u, r)\right] n_{0 \mathrm{c}}(u, r)
$$

\section{Calculation of wear}

\subsection{Tooth contact analysis}

To calculate the wear for all the points on the tooth profile, it is important that for any point on the tooth profile of the drive gear, there is a corresponding contact point on the driven gear. Though several methods have been proposed earlier for gear tooth contact analysis [43, 44], this study employs an analytical method.

Figure 3 shows the coordinate systems for the calculation of contact points. Points $O_{I}$ and $O_{O}$ are respectively the drive and driven gear center. The coordinate system $S_{F}\left(O_{I}-x_{F} y_{F} z_{F}\right)$ is fixed on the ground with $x_{F}$-axis along the center distance vector

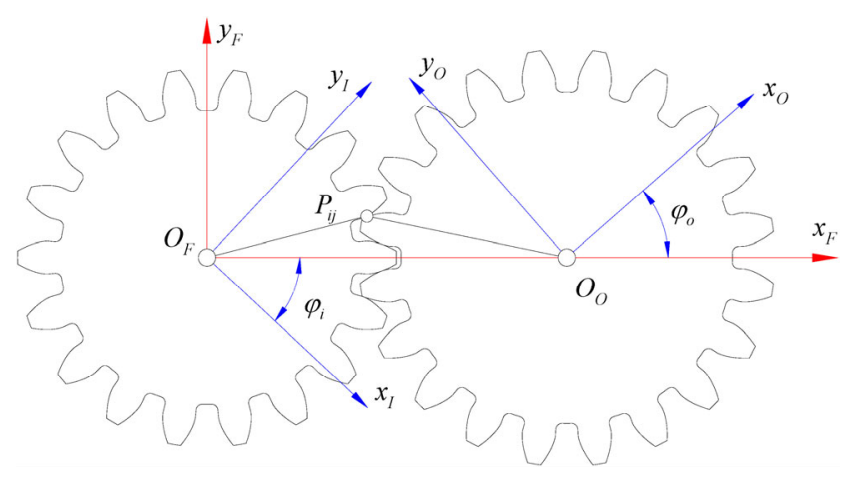

Fig. 3 Coordinate systems for calculation of the contact points.

$\overrightarrow{O_{I} O_{O}}$. The coordinate system $S_{I}\left(O_{I}-x_{I} y_{I} z_{I}\right)$ is attached on the drive gear with its angle relative to $S_{F}$ being the rotating angle of the drive gear $\varphi_{i}$. The coordinate system $S_{O}\left(O_{O}-x_{O} y_{O} z_{O}\right)$ is attached on the driven gear with its angle relative to $S_{F}$ being the rotating angle of drive gear $\varphi_{0}$. The coordinate transformation from the drive and driven gears to the fixed coordinate $S_{F}$ can be obtained as follows:

$$
\left\{\begin{aligned}
M_{F I}\left(\varphi_{I}\right) & =\left[\begin{array}{cccc}
\cos \left(\varphi_{I}\right) & -\sin \left(\varphi_{I}\right) & 0 & 0 \\
\sin \left(\varphi_{I}\right) & \cos \left(\varphi_{I}\right) & 0 & 0 \\
0 & 0 & 1 & 0 \\
0 & 0 & 0 & 1
\end{array}\right] \\
M_{F O}\left(\varphi_{o}\right) & =\left[\begin{array}{cccc}
\cos \left(\varphi_{o}\right) & -\sin \left(\varphi_{o}\right) & 0 & 0 \\
\sin \left(\varphi_{o}\right) & \cos \left(\varphi_{o}\right) & 0 & 0 \\
0 & 0 & 1 & E_{I O} \\
0 & 0 & 0 & 1
\end{array}\right]
\end{aligned}\right.
$$

where $E_{I O}$ is the center distance of the gear pair.

The tooth profile of the drive and driven gears are redefined as $r_{\mathrm{G} i}(u, r)$ and $r_{\mathrm{Go}}(u, r)$, respectively, and the tooth surface in $S_{F}$ can be obtained as follows:

$$
\left\{\begin{array}{l}
\boldsymbol{r}_{F i}\left(u, r, \varphi_{I}\right)=\boldsymbol{M}_{F I}\left(\varphi_{I}\right) \boldsymbol{r}_{G i}(u, r) \\
\boldsymbol{r}_{F o}\left(u, r, \varphi_{\mathrm{o}}\right)=\boldsymbol{M}_{F o}\left(\varphi_{o}\right) \boldsymbol{r}_{G o}(u, r)
\end{array}\right.
$$

Similarly, the tooth normals in $S_{F}$ are obtained as follows:

$$
\left\{\begin{array}{l}
\boldsymbol{n}_{F i}\left(u_{i}, r_{i}, \varphi_{I}\right)=\boldsymbol{M}_{F I}\left(\varphi_{I}\right) \boldsymbol{n}_{G i}\left(u_{i}, r_{i}\right) \\
\boldsymbol{n}_{F o}\left(u_{o}, r_{o}, \varphi_{o}\right)=\boldsymbol{M}_{F o}\left(\varphi_{o}\right) \boldsymbol{n}_{G o}\left(u_{o}, r_{o}\right)
\end{array}\right.
$$

In addition, the velocity of contact points in the coordinate system $S_{F}$ relative to the drive and driven gears are respectively defined as follows: 


$$
\left\{\begin{array}{l}
\boldsymbol{v}_{i}\left(u_{i}, r_{i}, \varphi_{I}\right)=\left[\begin{array}{l}
0 \\
0 \\
1
\end{array}\right] \times \boldsymbol{r}_{F i}\left(u_{i}, r_{i}, \varphi_{I}\right) \\
\boldsymbol{v}_{o}\left(u_{o}, r_{o}, \varphi_{o}\right)=\left[\begin{array}{c}
0 \\
0 \\
\varphi_{o} / \varphi_{I}
\end{array}\right] \times \boldsymbol{r}_{F o}\left(u_{o}, r_{o}, \varphi_{I}\right)
\end{array}\right.
$$

Further, the relative velocity of the contact points between the drive and driven gears is obtained as follows:

$$
v_{i o}\left(u_{i}, r_{i}, u_{o}, r_{o}, \varphi_{I}, \varphi_{o}\right)=v_{i}\left(u_{i}, r_{i}, \varphi_{I}\right)-v_{o}\left(u_{o}, r_{o}, \varphi_{o}\right)
$$

Thus, for any conjugate point, including parameter $u_{i}, r_{i}$ in the drive gear and $u_{o}, r_{o}$ in the driven gear, the following conditions must be satisfied:

$$
\left\{\begin{array}{l}
n_{F i}\left(u_{i}, r_{i}, \varphi_{I}\right)=n_{F o}\left(u_{i}, r_{i}, \varphi_{I}\right) \\
\boldsymbol{r}_{F i}\left(u_{i}, r_{i}, \varphi_{I}\right)=\boldsymbol{r}_{F o}\left(u_{o}, r_{o}, \varphi_{I}\right) \\
\boldsymbol{n}_{F i}\left(u_{i}, r_{i}, \varphi_{I}\right) v_{i o}\left(u_{i}, r_{i}, u_{o}, r_{o}, \varphi_{I}, \varphi_{o}\right)=\mathbf{0}
\end{array}\right.
$$

This implies that for any point $P_{i}\left(u=u_{i}, r=r_{i}\right)$ on the tooth of the drive gear, the angular position of the drive $\varphi_{I}$, angular position of the driven gear $\varphi_{0}$, and the contact point $P_{o}\left(u=u_{o}, r=r_{o}\right)$ on the tooth of the driven gear can be obtained.

For spur gears, the tooth surface can be simplified as a planar curve. Therefore, the curvature of the drive gear $K_{i}$ and that of the driven gear $K_{o}$ can be obtained based on the planar curvature equation. The relative curvature is defined as follows:

$$
K_{i o}=K_{i}+K_{o}
$$

\subsection{Contact force}

As shown in Fig. 4, for any moment during the driving process defined by subscript $j$, suppose the instant contact point number is $n_{c j}$, then each of the points is defined as $P_{i j}\left(j=1,2 \cdots n_{c j}\right)$. The total torque applied to the driven gear is shared by these contact points.

$$
\boldsymbol{T}_{o}=\sum_{j}^{n_{c}} \boldsymbol{F}_{j} \times \boldsymbol{r}_{j}
$$

where $T_{o}$ is the load applied to the driven gear, and $\boldsymbol{r}_{j}$ is the position vector of the contact point. $\boldsymbol{F}_{j}$ is the

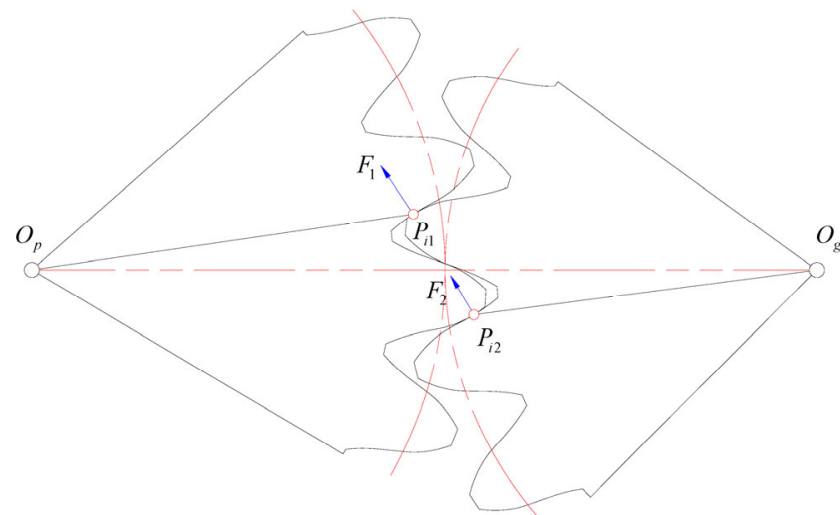

Fig. 4 Modification of tooth profile for the basic rack

normal contact force for each point, which is calculated as follows:

$$
\boldsymbol{F}_{j}=\boldsymbol{C}_{j} \delta_{j} \boldsymbol{n}_{j}
$$

where $C_{j}$ is the comprehensive stiffness matrix, $\delta_{j}$ is the total deformation of the gear teeth, and $n_{j}$ is the unit normal vector of the contact point.

Due to the complicated tooth geometry of spur gears, no accurate analytical algorithm has been proposed for force calculation so far. Therefore, Simon proposed an empirical method based on finite element method [16]. However, this study was established to be inaccurate and applicable only to standard involute gears. Thus, our current work applies the finite element method directly for force investigation.

The maximum pressure at each contact point can be calculated based on the Hertzian contact model $[45,46]$ as follows:

$$
P_{\mathrm{H}}=\frac{2 F_{j}}{\pi a_{j} b}
$$

where $b$ is the contact width, which is equal to the tooth width $l$ in case of spur gears; $a_{j}$ is the semi-Hertzian contact width, calculated as follows:

$$
a_{j}=\sqrt{\frac{4 F_{j}}{\pi b} \frac{\frac{1-v_{i}^{2}}{E_{i}}+\frac{1-v_{o}^{2}}{E_{o}}}{K_{i o}}}
$$

where $v_{i}$ and $v_{o}$ are the Poisson's ratios for the drive and driven gears, respectively, and $E_{i}$ and $E_{o}$ are the Young's modulus for the drive and driven gears, respectively. 


\subsection{Wear depth calculation}

Based on the generalized Archard's wear equation [7], the wear depth can be calculated as follows:

$$
h=\int_{0}^{s} K_{\mathrm{w}} P_{\mathrm{H}} \mathrm{d} s
$$

where $K_{w}$ is the wear coefficient, which is set to $5 \times 10^{-16} \mathrm{~m}^{2} / \mathrm{N}$ [15]. This equation can also be rewritten differently as follows:

$$
h_{i}=K_{\mathrm{w}} P_{\mathrm{H}} s_{\mathrm{j}}+h_{i-1}
$$

where $s_{i}$ is the slider distance in each micro segment, which can be obtained based on the point contact features of the gear surface.

For drive gear:

$$
s_{i}=a_{j} \frac{\left|v_{i o}\left(u_{i}, r_{i}, u_{o}, r_{o}, \varphi_{I}, \varphi_{o}\right)\right|}{\left|v_{i}\left(u_{i}, r_{i}, \varphi_{I}\right)\right|}
$$

For driven gear:

$$
s_{i}=a_{j} \frac{\left|v_{i o}\left(u_{i}, r_{i}, u_{o}, r_{o}, \varphi_{I}, \varphi_{o}\right)\right|}{\left|v_{o}\left(u_{o}, r_{o}, \varphi_{o}\right)\right|}
$$

\section{Example and discussion}

\subsection{Finite element analysis}

As discussed earlier, the force applied to the gear contact point is obtained through a finite element analysis in the third commercial software ANSYS, and the wear depth can be calculated based on the value of force.

In this research, the planet gear and sun gear of an epicyclical transmission used in the wheel hub of an electric automobile is considered as an example. The basic parameters of the gear pair are shown in Table 1 .

As illustrated in Fig. 5, four tooth pairs are used to maintain the boundary adequately far for the tooth-

Table 1 Basic design parameters for gear pair.

\begin{tabular}{cc}
\hline Module $(\mathrm{mm})$ & 1.25 \\
Tooth number of pinion & 19 \\
Tooth number of gear & 66 \\
Addendum coefficient & 1 \\
Dedendum coefficient & 1.25 \\
Face width & 20 \\
\hline
\end{tabular}

Table 2 Setting for the finite element analysis.

\begin{tabular}{cc} 
Young's modulus & $2.1 \times 10^{5} \mathrm{MPa}$ \\
Poisson's ratio & 0.3 \\
Contact type & Frictionless \\
Contact formulation & Pure penalty \\
Master surfaces & Pinion surface \\
Slave surfaces & Gear surface \\
Torque applied the gear & $1,000 \mathrm{~N} \cdot \mathrm{mm}$ \\
Velocity of the pinion & $6.28 \mathrm{rad} / \mathrm{s}$ \\
Analysis time & $0.08 \mathrm{~s}$ \\
Analysis steps & 30 \\
\hline
\end{tabular}

loaded areas. The finite model is meshed with SOLID187 elements, which are high-order 3-D 10-node elements with quadratic displacement behavior and well suited for large strain deflections. The material is steel with a Young's modulus of $E=2.1 \times 10^{5} \mathrm{MPa}$ and Poisson's ratio of 0.3 . The contact type, without considering the frictional force, is set to be frictionless.

The pinion tooth flanks are set as master surfaces (CONTACT174 elements), and the wheel tooth flanks are set as slave surfaces (TARGE170 elements). Pure penalty formulation is used for calculating the contact.

To investigate the contact force at each point of time during a meshing cycle, the analysis type is set as transient structure. During the analysis, the revolution joints are set on the inner bore surface of the pinion and the gear. The velocity load is set to 6.28 on the pinion revolution, and a torque is set on the gear revolution. The analysis time is set to $0.08 \mathrm{~s}$, and the sub step is set to 30 to enable the tooth surface pair contact from the root to the tip.

A convergence study is conducted with a fine mesh of elements at the contact region to assess the approximate number of elements required. The contact pressure at the initial position, obtained through the convergence study, is shown in Fig. 6. It is observed

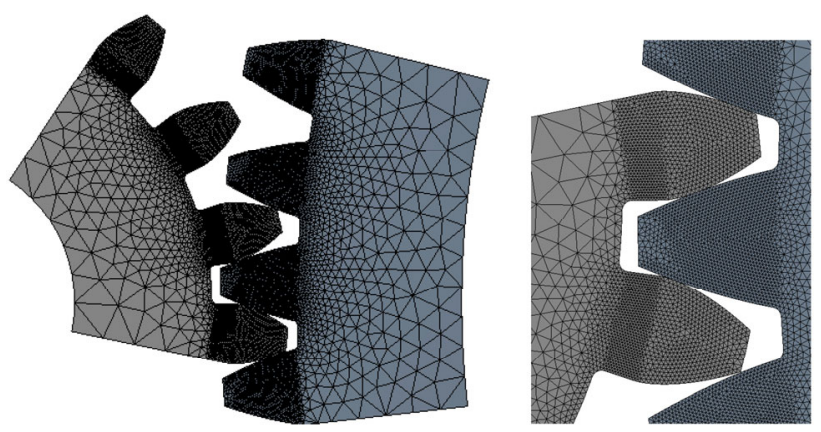

Fig. 5 Finite element model for spur gear. 


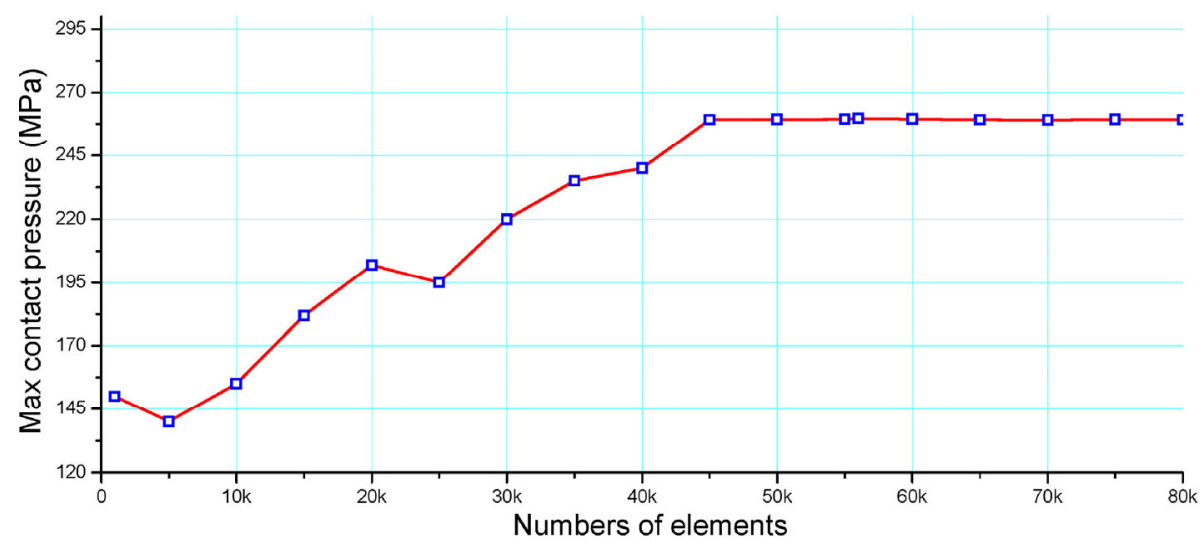

Fig. 6 Contact pressure obtained through convergence study.

that the contact pressure level converges to a constant level, when the number of elements is 45,000 and over. Thus, the model is discretized by a very fine mesh with 60,000 elements $(60,000>$ convergence level $)$.

\subsection{Results and discussion}

In this study, for investigation of the influence of cutter modification on wear, a standard gear without cutter modification is denoted as Case 0, while the eight modified gears with different cutter modification parameters are denoted as Case 1 to Case 8 as shown in Table 3. Among them, for Case 1, Case 3, Case 5, and Case 7 , four magnitude ranges are set to investigate the influence of the modification range. With any modification range of Case 1, Case 3, Case 5, and Case 7,

Table 3 Modification parameters and tooth geometry in each case.

\begin{tabular}{lccc}
\hline & $\begin{array}{c}\text { Modification } \\
\text { magnitude } \xi\end{array}$ & $\begin{array}{c}\text { Modification } \\
\text { range } \mu\end{array}$ & Tooth geometry \\
Case 0 & 0 & 0 \\
Case 1 & 0.2 & 0.75 \\
Case 2 & 0.4 & 0.75 \\
\hline
\end{tabular}

a doubled modification magnitude is considered, as shown correspondingly in Case 2, Case 4, Case 6, and

(Continued)

\begin{tabular}{|c|c|c|c|}
\hline & $\begin{array}{l}\text { Modification } \\
\text { magnitude } \xi\end{array}$ & $\begin{array}{l}\text { Modification } \\
\text { range } \mu\end{array}$ & Tooth geometry \\
\hline Case 3 & 0.13 & 0.5 & \\
\hline Case 4 & 0.26 & 0.5 & \\
\hline Case 5 & 0.08 & 0.25 & \\
\hline Case 6 & 0.16 & 0.25 & \\
\hline Case 7 & 0.055 & 0 & \\
\hline Case 8 & 0.11 & 0 & \\
\hline
\end{tabular}


Case 8 , to investigate the influence of modification magnitude. It is worth noting that the influence of the modification magnitude is different with different modification ranges. Thus, the modifycation magnitude should not be considered the same under different modification ranges.

Varied tooth geometry against each case is also shown in the table. The influence of the modification parameters on the tooth shape can be deduced from the tooth geometry. The modification range determines the starting point of modification, and along with its decrease, the modified tooth shows a higher deviation from the standard tooth in Case 0 . The modification magnitude influences the deviation magnitude, and along with its increase, the tooth tip and tooth root decline.

Figure 7 shows the normal contact force at different points in the gear. It is observed that the contact force is not symmetrical without cutter modification (Case 0 ), and it becomes relatively symmetrical with cutter modification (Case 1-Case 8). In addition, the maximum contact force is basically similar for all cases, implying that the maximum contact force is not influenced by cutter modification. However, the total contact force is increases with an increase in either tooth modification magnitude or modification range.

Figure 8 shows the semi contact width at different points in the gear. It is observed that the curve shape becomes symmetrical with cutter modification. In addition, for Case 1-Case 8, the value of contact width is almost the same at the middle tooth height point. However, at other points, it is increased with an increase in either modification magnitude or modification range. This can be explained by the change of contact force and relative curvature.

Figure 9 shows the sliding distance at different points in the gear. It is observed that the sliding distance decreases with an increase in the modification

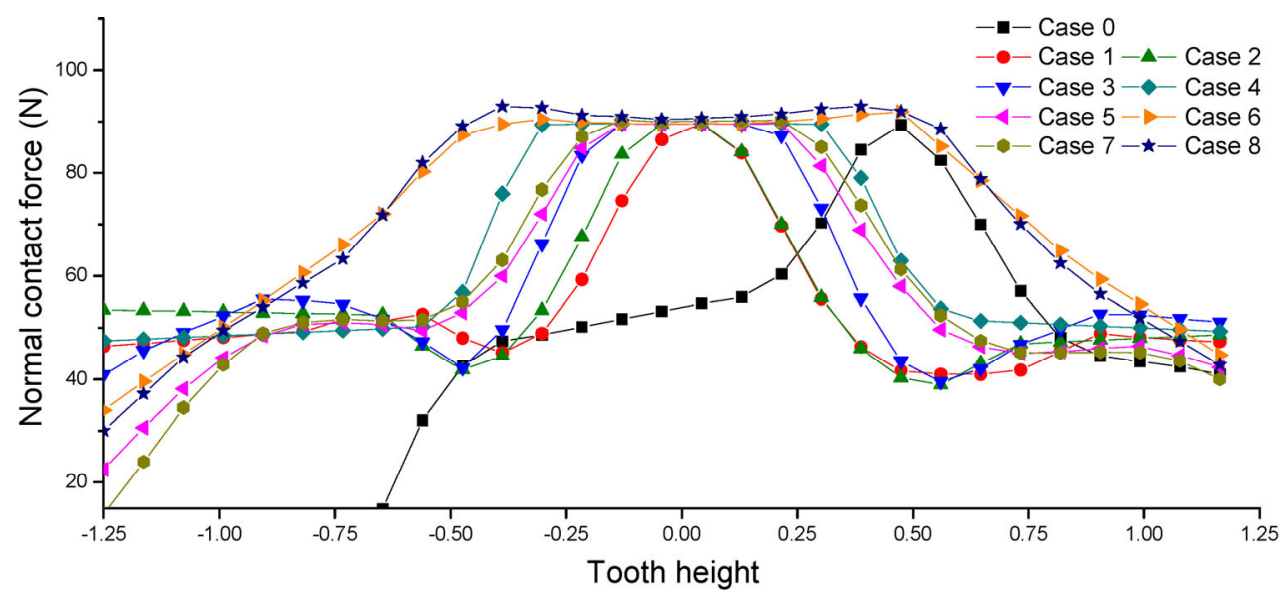

Fig. 7 Normal contact force at different points in the gear.

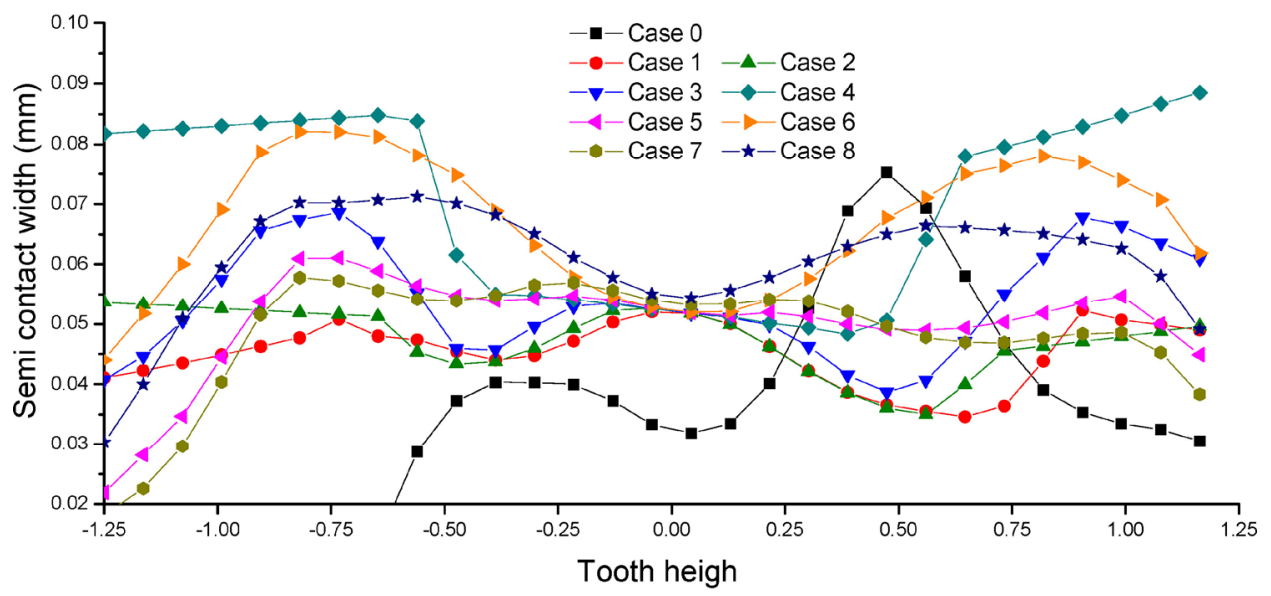

Fig. 8 Semi contact width at different points in the gear. 
magnitude and modification range. This can be explained by the fact that the distance between the contact point and the corresponding instant center decreases with an increase in modification.

Figure 10 shows the wear depth at different points in the gear. For the standard case (Case 0), the wear depth is much higher near the tooth tip and lower near the tooth root. For the gear with cutter modification, the wear near the tooth tip reduces, while that near the tooth root increases. Case 4 is observed to be the best modification, in which the wear near the tooth tip and that near the tooth root are almost the same, and the maximum wear depth is lower than that of the standard gear.

Therefore, with proper cutter modification (Case 4), the surface wear becomes even, and the maximum wear depth is lower, implying that reshaping tooth geometry through cutter modification can enhance the wear resistance for spur gears.

\section{Conclusions}

This study establishes a mathematic model for modified gears generated by modified rack cutters and investigates wear performance under the different modifications of the cutter through a mixed finite element model and analytical approach. Based on the results and discussions, several conclusions are drawn as follows:

(1) With the proposed cutter modification, the gear flank wear reduces near the tooth tip, while it increases near the tooth root.

(2) With proper cutter modification, the gear flank wear is uniform throughout the flank, as the maximum wear depth is decreased, which enhances the wear resistance for spur gears (as shown in Case 4).

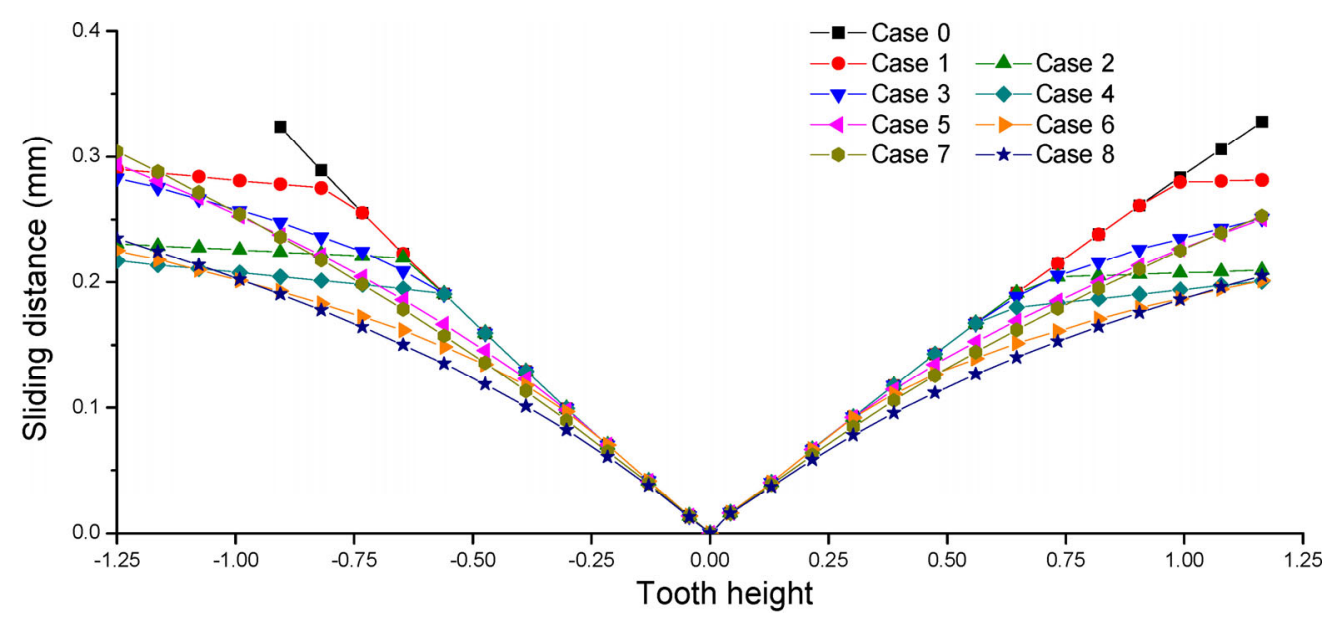

Fig. 9 Sliding distance at different points in the gear.

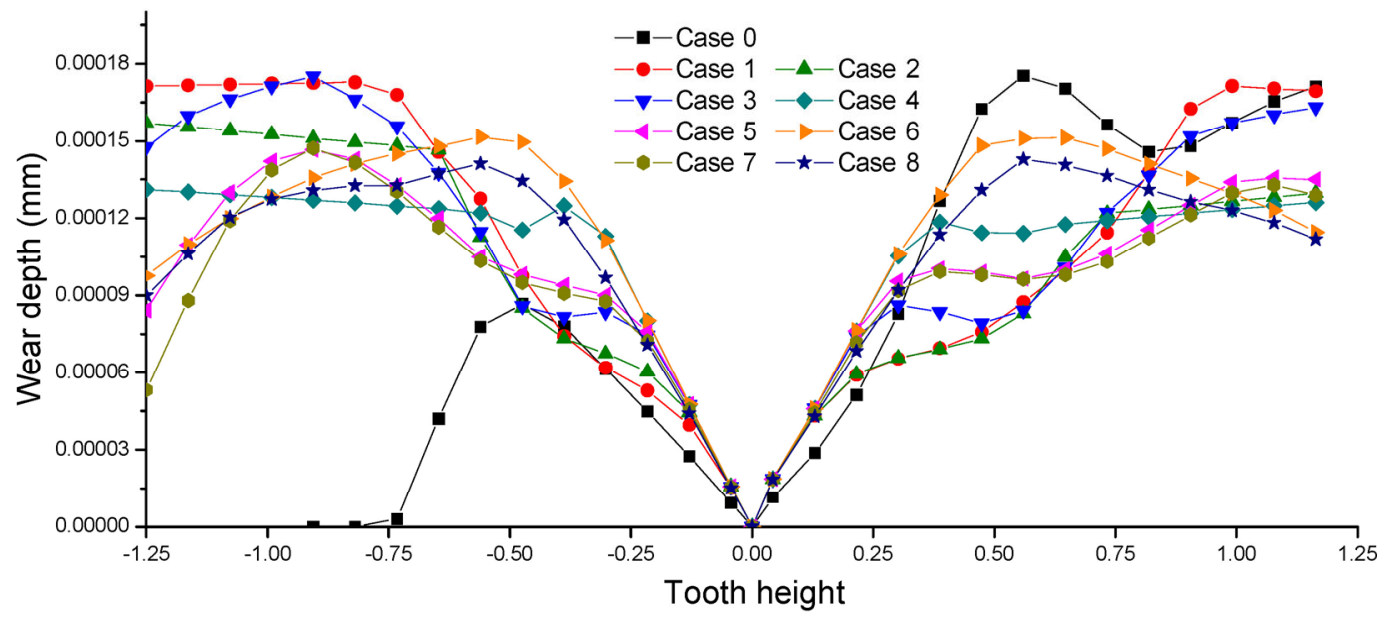

Fig. 10 Wear depth at different points in the gear. 


\section{Acknowledgements}

The authors would like to thank the National Natural Science Foundation of China (Nos. 51805062 and 51805060) for their support in conducting this research.

Open Access: This article is licensed under a Creative Commons Attribution 4.0 International License, which permits use, sharing, adaptation, distribution and reproduction in any medium or format, as long as you give appropriate credit to the original author(s) and the source, provide a link to the Creative Commons licence, and indicate if changes were made.

The images or other third party material in this article are included in the article's Creative Commons licence, unless indicated otherwise in a credit line to the material. If material is not included in the article's Creative Commons licence and your intended use is not permitted by statutory regulation or exceeds the permitted use, you will need to obtain permission directly from the copyright holder.

To view a copy of this licence, visit http://creativecommons.org/licenses/by/4.0/.

\section{References}

[1] Litvin F L. Gear Geometry and Applied Theory. Cambridge (UK): Cambridge University Press, 2004.

[2] Zheng F Y, Zhang M D, Zhang W Q, Guo X D. Research on the Tooth Modification in Gear Skiving. J Mech Des 140(8): 084502 (2018)

[3] Fuentes A, Ruiz-Orzaez R, Gonzalez-Perez I. Computerized design, simulation of meshing, and finite element analysis of two types of geometry of curvilinear cylindrical gears. Comput Methods Appl Mech Eng 272: 321-339 (2014)

[4] Zheng F Y, Hua L, Han X H, Li B, Chen D F. Linkage model and manufacturing process of shaping non-circular gears. Mech Mach Theory 96: 192-212 (2016)

[5] Zheng F Y, Hua L, Han X H, Li B, Chen D F. Synthesis of shaped noncircular gear using a three-linkage computer numerical control shaping machine. J Manuf Sci Eng 139(7): 071003 (2017)

[6] Zhou Y, Wang S, Wang L, Tang J, Chen Z C. CNC milling of face gears with a novel geometric analysis. Mech Mach Theory 139: 46-65 (2019)

[7] Choy F K, Polyshchuk V, Zakrajsek J J, Handschuh R F, Townsend D P. Analysis of the effects of surface pitting and wear on the vibration of a gear transmission system. Tribol Int 29(1): 77-83 (1996)

[8] Ziaran S, Darula R. Determination of the state of wear of high contact ratio gear sets by means of spectrum and cepstrum analysis. J Vib Acoust 135(2): 021008 (2013)

[9] Zhang R L, Gu F S, Mansaf H, Wang T, Ball A D. Gear wear monitoring by modulation signal bispectrum based on motor current signal analysis. Mech Syst Signal Process 94: 202-213 (2017)

[10] Kuang J H, Lin A D. The effect of tooth wear on the vibration spectrum of a spur gear pair. J Vib Acoust 123(3): 311-317 (2001)

[11] Archard J F. Contact and rubbing of flat surfaces. J Appl Phys 24(8): 981-988 (1953)

[12] Andersson S. Partial EHD theory and initial wear of gears. Ph.D Thesis. Stockholm (Sweden): Royal Institute of Technology, 1975.

[13] Wu S F, Cheng H S. Sliding wear calculation in spur gears. J Tribol 115(3): 493-500 (1993)

[14] Flodin A, Andersson S. Simulation of mild wear in helical gears. Wear 241(2): 123-128 (2000)

[15] Flodin A, Andersson S. A simplified model for wear prediction in helical gears. Wear 249(3-4): 285-292 (2001)

[16] Simon V. Load and stress distributions in spur and helical gears. J Mech Trans Autom Des 110(2): 197-202 (1988)

[17] Brauer J, Andersson S. Simulation of wear in gears with flank interference-A mixed FE and analytical approach. Wear 254(11): 1216-1232 (2003)

[18] Bajpai P, Kahraman A, Anderson N E. A surface wear prediction methodology for parallel-axis gear pairs. $J$ Tribol 126(3): 597-605 (2004)

[19] Kahraman A, Bajpai P, Anderson N E. Influence of tooth profile deviations on helical gear wear. $J$ Mech Des 127(4): 656-663 (2005)

[20] Tunalioğlu M S, Tuç B. Theoretical and experimental investigation of wear in internal gears. Wear 309(1-2): 208-215 (2014)

[21] Brandão J A, Martins R, Seabra J H O, Castro M J D. Calculation of gear tooth flank surface wear during an FZG micropitting test. Wear 311(1-2): 31-39 (2014)

[22] Masjedi M, Khonsari M M. On the prediction of steady-state wear rate in spur gears. Wear 342-343: 234-243 (2015)

[23] Henneberg M, Eriksen R L, Jørgensen B, Fich J. A quasistationary approach to particle concentration and distribution in gear oil for wear mode estimation. Wear 324-325: 140-146 (2015)

[24] Mao K. Gear tooth contact analysis and its application in the reduction of fatigue wear. Wear 262(11-12): 1281-1288 (2007) 
[25] İmrek H, Düzcükoğlu H. Relation between wear and tooth width modification in spur gears. Wear 262(3-4): 390-394 (2007)

[26] Karpat F, Ekwaro-Osire S. Influence of tip relief modification on the wear of spur gears with asymmetric teeth. Tribol Trans 51(5): 581-588 (2008)

[27] Prabhu Sekar R, Sathishkumar R. Enhancement of wear resistance on normal contact ratio spur gear pairs through non-standard gears. Wear 380-381: 228-239 (2017)

[28] Prabhu Sekar R, Muthuveerappan G. A balanced maximum fillet stresses on normal contact ratio spur gears to improve the load carrying capacity through nonstandard gears. Mech Based Des Struct Mach 43(2): 150-163 (2015)

[29] Zhou C J, Xiao Z L, Chen S Y, Han X. Normal and tangential oil film stiffness of modified spur gear with non-Newtonian elastohydrodynamic lubrication. Tribol Int 109: 319-327 (2017)

[30] Shih Y P, Chen S D. Free-form flank correction in helical gear grinding using a five-axis computer numerical control gear profile grinding machine. J Manuf Sci Eng 134(4): 041006 (2012)

[31] Zheng F Y, Hua L, Han X H. The mathematical model and mechanical properties of variable center distance gears based on screw theory. Mech Mach Theory 101: 116-139 (2016)

[32] Zheng F Y, Zhang M D, Zhang W Q, Tan R L, Guo X D. On the deformed tooth contact analysis for forged bevel gear modification. Mech Mach Theory 135: 192-207 (2019)

[33] Liu X Z, Yang Y H, Zhang J. Investigation on coupling effects between surface wear and dynamics in a spur gear system. Tribol Int 101: 383-394 (2016)

[34] Bouzakis K D, Kombogiannis S, Antoniadis A, Vidakis N. Gear hobbing cutting process simulation and tool wear prediction models. J Manuf Sci Eng 124(1): 42-51 (2002)

[35] Bouzakis K D, Friderikos O, Tsiafis I. FEM-supported simulation of chip formation and flow in gear hobbing of spur and helical gears. CIRP J Manuf Sci Technol 1(1): 18-26 (2008)

[36] Claudin C, Rech J. Development of a new rapid

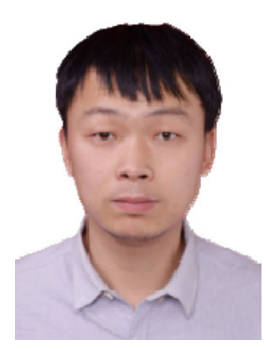

characterization method of hob's wear resistance in gear manufacturing-Application to the evaluation of various cutting edge preparations in high speed dry gear hobbing. J Mater Process Technol 209(11): 5152-5160 (2009)

[37] Karpuschewski B, Beutner M, Köchig M, Härtling C. Influence of the tool profile on the wear behaviour in gear hobbing. CIRP J Manuf Sci Technol 18: 128-134 (2017)

[38] Jiang J K, Fan Z D. High-order tooth flank correction for a helical gear on a six-axis CNC hob machine. Mech Mach Theory 91: 227-237 (2015)

[39] Zheng F Y, Hua L, Chen D F, Han X H. Generation of noncircular spiral bevel gears by face-milling method. J Manuf Sci Eng 138(8): 081013 (2016)

[40] Zheng F Y, Hua L, Han X H, Chen D F. Generation of noncircular bevel gears with free-form tooth profile and curvilinear tooth lengthwise. J Mech Des 138(6): 064501 (2016)

[41] Li S T. Gear contact model and loaded tooth contact analysis of a three-dimensional, thin-rimmed gear. J Mech Des 124(3): 511-517 (2002)

[42] Zhou Y, Wu Y, Wang L, Tang J, Ouyang H. A new closed-form calculation of envelope surface for modeling face gears. Mech Mach Theory 137: 211-226 (2019)

[43] Guan Y B, Fang Z D, Yang X H, Chen G D. Tooth contact analysis of crown gear coupling with misalignment. Mech Mach Theory 126: 295-311 (2018)

[44] Tran V T, Hsu R H, Tsay C B. Tooth contact analysis of double-crowned involute helical pairs shaved by a crowning mechanism with parallel shaving cutters. Mech Mach Theory 79: 198-216 (2014)

[45] Hu Z H, Ding H, Peng S D, Tang Y, Tang J Y. Numerical determination to loaded tooth contact performances in consideration of misalignment for the spiral bevel gears. Int J Mech Sci 151: 343-355 (2019)

[46] Diez-Ibarbia A, Fernandez-del-Rincon A, De-Juan A, Iglesias M, Garcia P, Viadero F. Frictional power losses on spur gears with tip reliefs. The load sharing role. Mech Mach Theory 112: 240-254 (2017)

current position is an associate professor in Wuhan University of Technology. His research areas cover the gear design, gear manufacturing, geometry, mechanism, and so on. 


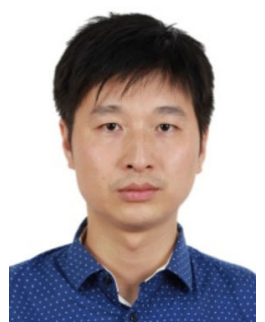

Jun ZHANG. He received the B.S., M.S., and Ph.D. degrees from Tianjin University, China, in 2002, 2004, and 2007, respectively. He is currently the deputy director of Gear Lab, Fuzhou University, and

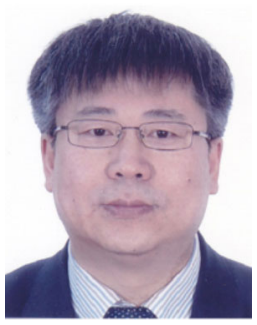

Ligang YAO. He received the B.S. and M.S. degrees from Northeast Petroleum University, China in 1984 and 1987, respectively, and the Ph.D. degree from the Harbin Institute of Technology, China in

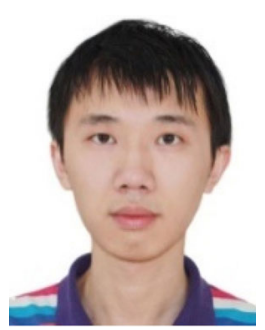

Rulong TAN. He received his Ph.D. degree in engineering from the State Key Laboratory of Mechanical Transmission, Chongqing University, he is also a chair professor at the School of Mechanical Engineering and Automation. He has published over 30 international journal papers and has served as a reviewer of related journals for years. His research interests include dynamic analysis, vibration control, and fault diagnosis.

1996. He is currently a professor at the School of Mechanical Engineering and Automation of Fuzhou University, China. His research focuses on the design and manufacturing of innovative gear transmissions, rehabilitation robotics, and geometric modeling.

China, in 2016. Now, he is an associate professor in Chongqing University of Technology. His research interests include bevel gear geometry, kinematics, and manufacturing. 